\title{
Research on Sustainable Green Supply Chain's Systematic Management Model
}

\author{
Lizhong Tong ${ }^{1, a}$, Xiaodong $\mathrm{Li}^{2, \mathrm{~b},{ }^{*}}$ \\ 1 School of Business, Sichuan University, Chengdu, Sichuan, P. R. China, 610065 \\ ${ }^{2}$ School of Business, Sichuan University, Chengdu, Sichuan, P. R. China, 610065 \\ alixiaodong0829@gmail.com, b15208107071@163.com
}

Keywords: Green Supply Chain Management; Sustainable; Systematic; Utilization rate of resources; Price growth rate; Investment recovery; Satisfaction

\begin{abstract}
Nowadays more and more enterprises start to carry out the Green Supply Chain Management practices, due to the increasing attention paid to environmental problems. However, in the research of Green Supply Chain Management there still exist deficiency of sustainability and worry of systematic. This article is to study the presently existing Green Supply Chain Management Models, and finally design a new type of Green Supply Chain Management Model with sustainability and systematic. The advantage of this model is to ensure that the supply chain can constantly protect the environment and to make each node of it profit through a more comprehensive management. In this new model four indicators are used: utilization rate of resources, price growth rate, investment recovery, and satisfaction, through which we hope to implement the Green Supply Chain Management sustainability and systematically, and to break through the locality and industry limitations in the study of Green Supply Chain Management.
\end{abstract}

\section{Introduction}

Currently, the environmental issues have become the focus of society, consumers have raised the environmental protection consciousness in daily life, companies have applied more environmentally-friendly concepts to industrial production. As an integrated production organization, the green management of the supply chain is also taken seriously.

Through literature research on Green Supply Chain Management, we find that systematic academic research on Green Supply Chain Management is not enough[1]. At present, the practice of Green Supply Chain Management mainly focus on cost reduction, economic growth and environment sustainability. For example, Srivastave believe that Green Supply Chain Management should be a combination of all aspects of environmental protection and the supply chain[2].

However, enterprises are facing many obstacles and uncertainties in the process of implementing GSCM. In the absence of a system management tool, it is difficult for an enterprise to adjust management strategies throughout the process of GSCM. Therefore, some scholars have engaged in designing GSCM model. For example, Feng Wei and Sifen Liu etc., they chose Guangxi manufacturing industries as research samples, designed a green supply chain management evaluation system based on circular economy, and set 24 indicators[3]. Jinsoo Kim and Jongtae Rhee studied the key factors of balanced scorecard that affect the profits of companies carrying out Green Supply Chain Management through empirical research.This paper seeks to fill this gap. Based on the extensive review of literature and summary of practices, the final system is to extract four indicators. The structure of this paper runs as follows: in section 2, some background information and theoretical development will be introduced. In section 3, the 4 indicators of the sustainability of GSCM 's systematical model will be termed and described, and in section 4, a detailed description of the steps of this model will be made. Section 5 comes to the conclusion, and it is believed that problems and potentials for future research still exist. 


\section{Literature Review}

GSCM concept evolved from green issues, the development of green issues is divided into four stages. Since 1960s, developed countries have started to pay attention to environmental issues. In 1970s, the government launched policies to support environmental protection, but the company took the reverse direction. From 1980s to 1990s, a number of senior executives of large companies gradually accepted the concept of sustainable development, and embarked on the green innovation. From 2010, the area of green issue has seen a rapid development, and scholars have begun to do a comprehensive study on green issues[4].

Since Michigan State University first proposed the concept of GSCM in 1996, different scholars have given GSCM different definitions. Testa and Iraldo proposed GSCM is a business expansion strategy, through which companies can have access to a better environmental performance[5]. According to Ortolani, GSCM can be described as the process of supply chain management, by which effects on environment will be measured and evaluated, and adverse management practices in production process will be reduced[6]. Rao and Holt believes GSCM is an advanced organizational philosophy[7]. Gilbert thinks that the GSCM is a combining of supply chain management and environmental thought[8]. Berman designed a green supply chain management model that includes four indicators. These four indicators are material recovery rate, core return rate, waste ratio, eco-efficiency[9]. Guoqing Huang and Fengyan Hua proposed a green supply chain model that includes five-level indicators and 32 secondary evaluation indexes through the GSC performance analysis[10]. In addition, Juhai Ji, Qingli Liu, Zhongxing Guo, built the evaluation system of green supply chain though the studying of iron and steel industry's green supply chain management[11]. However, the green supply chain performance evaluation methods should be further improved, it should avoid the influence of subjective factors on the green supply chain performance evaluation results[12].

\section{Definitions of Sustainable Green Supply Chain's Systematic Management Indicators}

Performance measurement is crucial to improve SCM. In this article, four indicators for the GSCM model are chosen. These four indicators are utilization rate of resources, price growth rate, investment recovery, and satisfaction .

Utilization Rate of Resources. Utilization rate of resources reflects the utilization degree of the material. In the green supply chain management process, we should reduce the input of natural resources and reduce waste output, and increase the recycling and reuse of waste. This index is the ratio of total expenses of resources consumption to net industrial output in the current year. The resources consumption of per unit of output value can directly reflect the effect of implementing green supply chain. In operation, this indicator should evaluate each individual entity of SCM, but it can also assess the resource utilization of the supply chain as a whole, so that the problems of utilization rate of resources can be found in the supply chain system.

Price Growth Rate. Green supply chain management companies should consider both ecological factors and economic factors. it will result in an increase in the supply chain entity's price gap if the enterprise which implements green supply chain management can not compensate for expenses with the using of technology, and also the price growth rate of the entire supply chain will increase finally. Therefore, the price can judge whether the contradiction between economic growth and environmental benefits of green supply chain exists in the implementation process.

Investment Recovery. The main index in the evaluation of an enterprise's profitability is the financial indicators, it's the important factors that affect investors' investment. It is necessary to consider economic factors and environmental conservation in GSCM process. Enterprises should not only cooperate with the upstream business, but also with upstream and downstream enterprises to achieve environmental protection[13]. However, there exists a fierce interest-competing relationship between upstream and downstream enterprises of the supply chain. In addition, the green supply 
chain management make some companies' costs higher than ever, resulting in an increase in the price growth rate, but there is no increased return on investment. It is harmful to the implementation of green supply chain management.

Satisfaction. Suppliers would be expected to meet to help and enterprise improve the environment performance of their products[14]. This is called GP, besides GP, enterprises also need to cooperate with their customers especially downstream buyers or end users to improve their environmental and profitability performance. By providing customer satisfaction, the profit will inevitably increase and a long lasting relationship of trust and appreciation will be developed between the firms and their consumers. Stank (1999) and Verhoef (2003) point out that customer satisfaction can improve enterprise's performance as the enterprise can affect customers' repeated purchase. Therefore, Satisfaction of the end user has a greater influence on the consumer behavior, and the satisfaction between upstream and downstream enterprises has a big effect on the collaboration of the supply chain system.

\section{Operational Method}

Green supply chain management represents a systematic thought, which is environmental program designed from the entire life cycle of the supply chain[15]. In the operation of this model, we need to start from the entire supply chain and collect the required data first, identify all aspects of the supply chain after making basic processing of the data, and design appropriate solutions to the problem identified finally. The procedure can be divided into three phases:(1) statistics processing; (2) problems identification; (3) solutions development.

Statistics Processing. The basic statistics needed for this model are utilization rate of resources, price growth rate, investment recovery, and satisfaction. The collected basic data need a simple processing, weight and price can be converted into utilization rate of resources and price growth rate, while investment recovery and satisfaction do not need to be treated.

Table 1 Statistics Processing

\begin{tabular}{|c|c|c|c|c|c|c|}
\hline & Price & $\begin{array}{l}\text { Price growth } \\
\text { rate }\end{array}$ & Weight & Utilization rate of resources & $\begin{array}{l}\text { Investment } \\
\text { recovery }\end{array}$ & $\begin{array}{l}\text { Satisfactio } \\
\mathrm{n}\end{array}$ \\
\hline Supplier & P1 & & W1 & & IR1 & S12 \\
\hline Logistic 1 & & & & & IR2 & \\
\hline Manufactur & P2 & $\mathrm{P} 21=(\mathrm{P} 2-\mathrm{P} 1) / \mathrm{P} 1$ & W2 & $\mathrm{U} 21=(\mathrm{W} 2-\mathrm{W} 1) / \mathrm{W} 1$ & IR3 & S21 \\
\hline er & & & W3 & $\mathrm{U} 32=(\mathrm{W} 3-\mathrm{W} 2) / \mathrm{W} 2$ & & S23 \\
\hline Logistic 2 & & & & & IR4 & \\
\hline $\begin{array}{l}\text { Distributor } \\
1\end{array}$ & P3 & $\mathrm{P} 32=(\mathrm{P} 3-\mathrm{P} 2) / \mathrm{P} 2$ & W4 & $\mathrm{U} 43=(\mathrm{W} 4-\mathrm{W} 3) / \mathrm{W} 3$ & IR5 & S32 \\
\hline Logistic 3 & & & W5 & U54=(W5-W4)/W4 & IR6 & S34 \\
\hline $\begin{array}{l}\text { Distributor } \\
2\end{array}$ & P4 & $\mathrm{P} 43=(\mathrm{P} 4-\mathrm{P} 3) / \mathrm{P} 3$ & $\begin{array}{l}\text { W6 } \\
\text { W7 }\end{array}$ & $\begin{array}{l}\mathrm{U} 65=(\mathrm{W} 6-\mathrm{W} 5) / \mathrm{W} 5 \\
\mathrm{U} 76=(\mathrm{W} 7-\mathrm{W} 6) / \mathrm{W} 6\end{array}$ & IR7 & $\begin{array}{l}\text { S43 } \\
\text { S45 }\end{array}$ \\
\hline Dictributor & $\cdots$ & $\cdots$ & W(2 & U $(2 \mathrm{~N}+2,2 \mathrm{~N}+1)$ & $\cdots$ & $\mathrm{S}(\mathrm{N}+2$, \\
\hline $\begin{array}{l}\text { Distributor } \\
\mathrm{N}\end{array}$ & $\begin{array}{l}\mathrm{P}(\mathrm{N}-1 \\
)\end{array}$ & $\begin{array}{l}\mathrm{P}(\mathrm{N}-1, \mathrm{~N}-2) \\
=(\mathrm{P}(\mathrm{N}-1)-\mathrm{P} \\
(\mathrm{N}-2)) / \mathrm{P}(\mathrm{N}-1)\end{array}$ & $\begin{array}{l}\mathrm{W}(2 \\
\mathrm{N}+3)\end{array}$ & $\begin{array}{l}=(\mathrm{W}(2 \mathrm{~N}+2)-\mathrm{W}(2 \mathrm{~N}+1)) / \mathrm{W}(2 \mathrm{~N} \\
+1) \\
\mathrm{U}(2 \mathrm{~N}+3,2 \mathrm{~N}+2) \\
=(\mathrm{W}(2 \mathrm{~N}+3)-\mathrm{W}(2 \mathrm{~N}+2)) / \mathrm{W}(2 \mathrm{~N} \\
+2)\end{array}$ & $\mathrm{IR}(\mathrm{N}+4)$ & $\begin{array}{l}\mathrm{N}+1) \\
\mathrm{S}(\mathrm{N}+2, \mathrm{~N}+ \\
3)\end{array}$ \\
\hline Logistic & & & & & $\mathrm{IR}(\mathrm{N}+5)$ & \\
\hline Consumer & & & $\begin{array}{l}\mathrm{W}(2 \\
\mathrm{N}+4)\end{array}$ & $\begin{array}{l}\mathrm{U}(2 \mathrm{~N}+4,2 \mathrm{~N}+3) \\
=(\mathrm{W}(2 \mathrm{~N}+4)-\mathrm{W}(2 \mathrm{~N}+3)) / \mathrm{W}(2 \mathrm{~N} \\
+3)\end{array}$ & & $\begin{array}{l}S(N+4) \\
S(N+5)\end{array}$ \\
\hline
\end{tabular}


we design a form based on the data needed of this model. form the first line is utilization rate of resources (U), price growth rate (P), investment recovery (IR), satisfaction (S). These indicators can be arranged as needed. Table1 operating points in this article: (1) manufacturers in the supply chain can also have multiple layers, there does not exist upstream or downstream relationship between the manufacturer parallel, but non-parallel relationship manufacturer dose. By a manufacturer1, manufacturer11, manufacturer12 to represent hierarchical relationships, manufacturer11and manufacturers12 for the same level, they belong to the downstream of manufacturer1. Final manufacturer is indicated by the manufacturer directly in table1. (2) The P value of price column is the suppliers, manufacturers, distributors' selling price, such as P1 represents the price which is supplier sold to manufacturers. Price growth rate among the producers and distributors represents for each node of supply chain's price growth, price growth rate among the producers and distributors on the lines of number represent for each node price growth, such as P21 is the growth rate of supplier sold to manufacturers price P1 and manufacturer sales price P2. Weight column needs to set up two weight values for manufacturers and distributors, representatives to the weight before node and the weight away node. Utilization rate of resources column is used for weight loss reaction of all aspects of the supply chain, including logistics. Satisfaction column values are set two in each of the satisfaction manufacturers and distributors, such as S21 and S23 represents manufacturer's satisfaction value for distributors and suppliers. Satisfaction value of consumer line also has two, $\mathrm{S}$ $(\mathrm{N}+4)$ is the consumer satisfaction value for terminal vendors, $\mathrm{S}(\mathrm{N}+5)$ is the consumer satisfaction for the whole supply chain degrees.

Problems Identification. After the first step, we need to find the green supply chain problems though statistics. U on behalf of the material's unreasonable use in the supply chain ; P and IR can react on the economic benefits of the supply chain, through a comprehensive assessment of these two indicators of to find the existing economic problems of the green supply chain management implementation ; $S$ to reflect the existing synergy and unfair competition problem of the supply chain. The problem identify principle as followed: (1) Locking the entity which both sides have low utilization rate of resources trough the statistics of table1, finding the cause of this problem.(2)Find out the lager price growth rate enterprises, whether low or high investment recovery rate, they all have certain economic problem. (3) We should find the problem From the enterprise's satisfaction evaluation value of upstream and downstream, the poor mutual satisfaction evaluation value enterprise should have some problems .(4) Labeled the questions companies in Table 2, and indicate the source of the problem. 
Table 2 Problems Identification

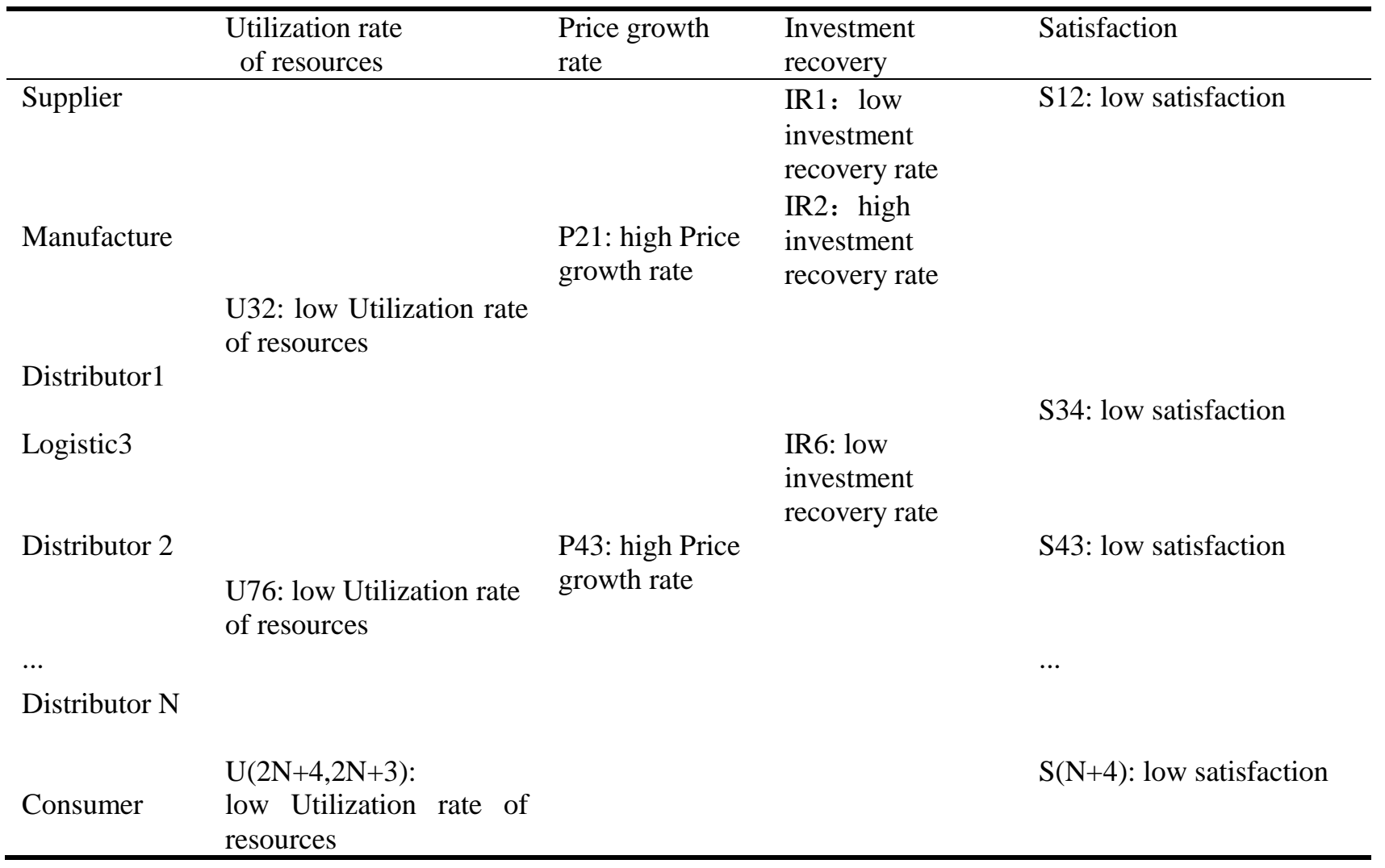

Solutions Development. The operation target of third phase is the question which is marked out in second stage. First, we need aggregate each entity's problems, as shown in Table 3 form, this form can be a systematic analysis of each business problem. Analysis the problems of every entity themselves and their downstream and upstream after the question summary, then defining the detailed cause of the problem. Secondly, design detailed solutions according to the cause of every problem (only design solutions for individual problems, repeat do not consider ). Finally, design the total solution according to all solutions, Merge duplicate solutions and adjust conflicting solutions during the process.

Table 3 Solutions Development

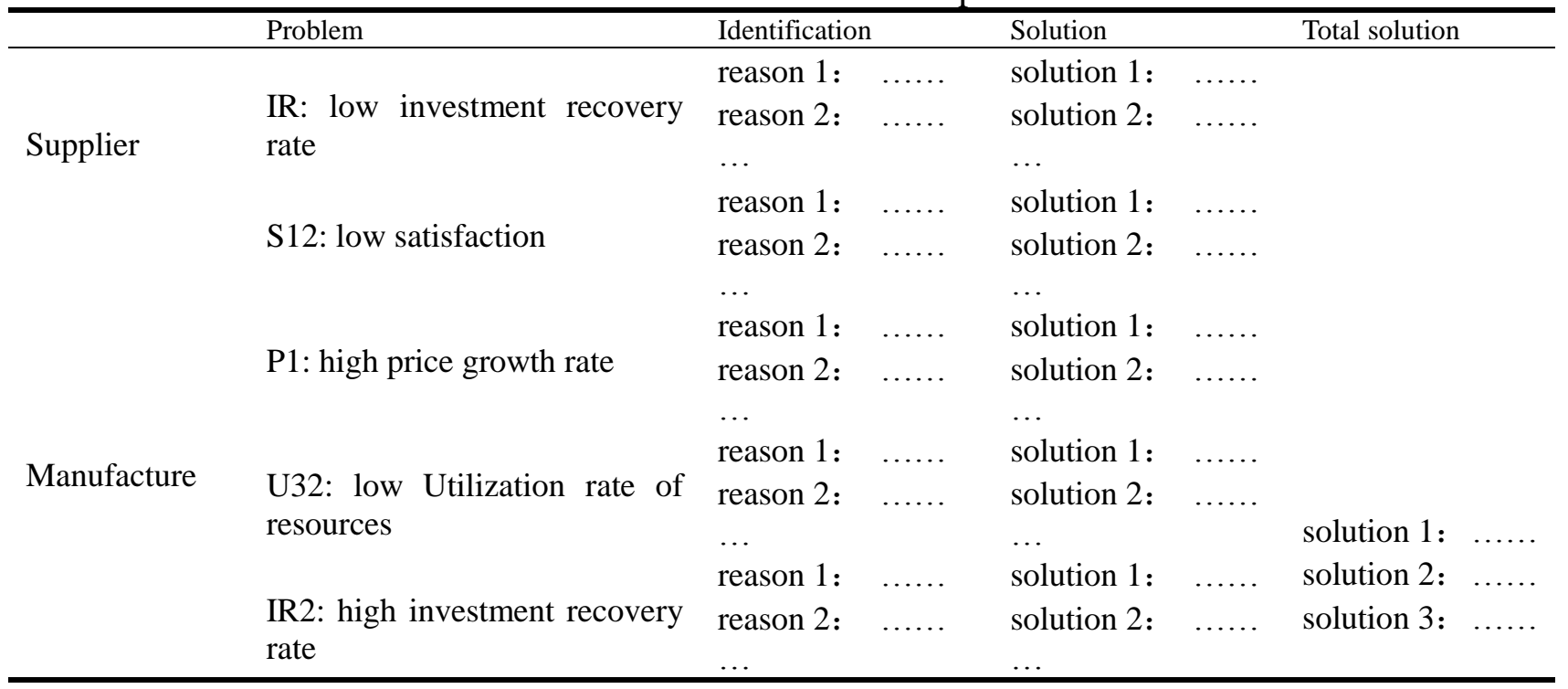




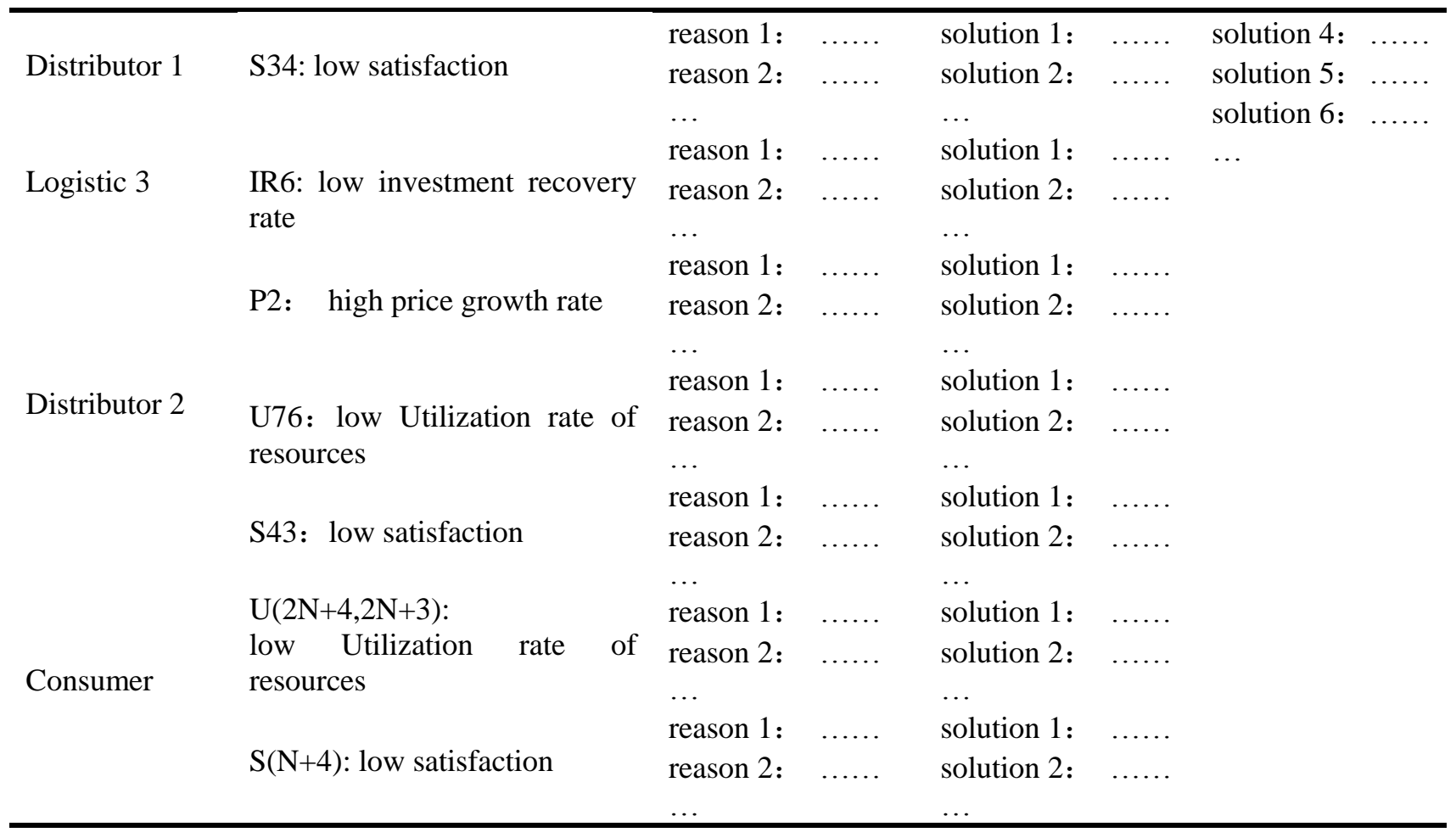

\section{Summary}

As stated in the beginning, the purpose of this study is to build a sustainable supply chain systematic management model that aims to break the limitations of industry restrictions of existing researches. We choose four indicators (utilization rate of resources, price growth rate, investment recovery, satisfaction) to combine the green supply chain's three aspects: environmental protection, economy and supply chain. We design the index's operation method, make the model more operational. Simultaneously, this model can be applied to a wide range, not only suitable for the management of the entire supply chain, but also for all supply chain enterprises' self-management, and there is no sectional restrictions.

\section{References}

[1] Muhammed , K., \& Nejra , O. (2013). Green supply chain management: A new movement towards healthier environment, Erbil:European Researcher, 55,7-2.

[2] Srivastava, S. (2007), Green supply-chain management: A state-of-the-art literature review. International Journal of Management Reviews, 9: 1, pp. 53-80.

[4] Schaper, M. (2002). The challenge of environmental responsibility and sustainable development: Implications for SME and entrepreneurship academics, http://www.kmu.unisg.ch/rencontres/band2002/F_09_Schaper. pdf. Accessed 3 October 2011.

[4] Schaper, M. (2002). The challenge of environmental responsibility and sustainable development: Implications for SME and entrepreneurship academics, http://www.kmu.unisg.ch/rencontres/band2002/F_09_Schaper. pdf. Accessed 3 October 2011.

[5] Testa, F. and Iraldo, F. (2010), Shadows and lights of GSCM (Green Supply Chain Management): Determinants and effects of these practices based on a multi-national study. Journal of Cleaner Production, 18: 10-11, pp. 9533-962. 
[7] Rao, P., \& Holt, D. (2005). Do green supply chains lead to competitiveness and economic performance? International Journal of Operations \& Production Management, 25 (9-10), 898-916.

[7] Rao, P., \& Holt, D. (2005). Do green supply chains lead to competitiveness and economic performance? International Journal of Operations \& Production Management, 25 (9-10), 898-916.

[8] Gilbert, S. (2000). Greening supply chain: Enhancing competitiveness through green productivity. Report of the Top Forum on Enhancing Competitiveness through Green Productivity held in the Republic of China. 25-27 May, 2000.

[9] Beauman, B. (1999). M.Designing the green supply cliain. Logisticsl Information Management. 12( 4):332- 342.

[10] Guoqing Huang \& Fengyan Hua. (2007). Green supply chain performance evaluation model research. Industrial Engineering Journal. 10(1), 116-129.

[11] Juhai Ji, Qingli Liu, Zhongxing Guo. Iron and steel enterprise performance evaluation of green supply chain management. Science and Technology Management Research, 16, 53-57.

[8] Gilbert, S. (2000). Greening supply chain: Enhancing competitiveness through green productivity. Report of the Top Forum on Enhancing Competitiveness through Green Productivity held in the Republic of China. 25-27 May, 2000.

[8] Gilbert, S. (2000). Greening supply chain: Enhancing competitiveness through green productivity. Report of the Top Forum on Enhancing Competitiveness through Green Productivity held in the Republic of China. 25-27 May, 2000.

[8] Gilbert, S. (2000). Greening supply chain: Enhancing competitiveness through green productivity. Report of the Top Forum on Enhancing Competitiveness through Green Productivity held in the Republic of China. 25-27 May, 2000.

[15] Fiksel, J. (1996). Design for environment: Creating eco-efficient products and processes. McGraw-Hill: New York. 